\title{
Highly Regulated Supramolecular Assembly of 2-O-Methylated $\alpha$-Cyclodextrin to Construct Vertically Oriented Microrods on Graphite
}

\author{
Justine M. Kalaw, ${ }^{1}$ Mizuki Kitagawa, ${ }^{1}$ Hajime Shigemitsu, ${ }^{1,2,3}$ and Toshiyuki Kida*1,2 \\ ${ }^{1}$ Department of Applied Chemistry, Graduate School of Engineering, Osaka University, 2-1 Yamada-oka, Suita, \\ Osaka 565-0871, Japan. \\ ${ }^{2}$ Integrated Frontier Research for Medical Science Division, Institute for Open and Transdisciplinary Research \\ Initiatives (OTRI), Osaka University, 2-1 Yamada-oka, Suita, Osaka 565-0871, Japan \\ ${ }^{3}$ Frontier Research Base for Global Young Researchers, Graduate School of Engineering, Osaka University, 2-1 \\ Yamada-oka, Suita, Osaka 565-0871, Japan \\ Email:kida@chem.eng.osaka-u.ac.jp
}

1. $\quad$ Experimental procedures

2. Spectral data of 2-Me- $\alpha-\mathrm{CD}$

3. SEM images of 2-Me- $\alpha-C D$ precipitates formed by mixing a methanol solution of 2-Me- $\alpha$-CD with different poor solvents

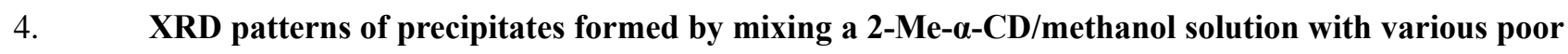
solvents and then standing at room temperature

5. Crystal structure of 2-Me- $\alpha-\mathrm{CD}$ - benzene inclusion complex

6. Crystal structure of 2-Me-a-CD - cyclohexane inclusion complex 


\section{Experimental procedures}

The ${ }^{1} \mathrm{H}$ and ${ }^{13} \mathrm{C}$ NMR spectra were recorded on $400 \mathrm{MHz}$ spectrometer (JEOL JNM-ECS400, JEOL Ltd., Japan). The MALDI-TOF mass spectrum was obtained using time-of-flight mass spectrometer (Bruker Autoflex® III, Bruker Corp., Japan). SEM measurements were performed with a JSM-6701F instrument (JEOL Ltd., Japan). Xray diffraction patterns of powder samples were obtained at room temperature on a Rigaku RINT InPlane/ultraX18SAXS-IP diffractometer using monochromatic $\mathrm{Cu}-\mathrm{K} \alpha$ radiation generated at $40 \mathrm{kV}, 200 \mathrm{~mA}$. The scan rate was $2 \theta=1^{\circ} \mathrm{min}^{-1}$ between $2 \theta=3^{\circ}$ and $30^{\circ}$. X-ray diffraction data for single crystal analysis were collected on a Rigaku R-AXIS RAPID diffractometer with a 2D area detector by using graphite-monochromatized $\mathrm{Cu} \mathrm{Ka}$ radiation $\left(\lambda=1.54178 \AA\right.$ ). Direct methods (SIR-2004) were used to solve the structure. ${ }^{1}$ All calculations were performed with the observed reflections $[I>2 \sigma(I)]$ by using the CrystalStructure crystallographic software package, ${ }^{2}$ except for refinement, which was performed using SHELXL-97. ${ }^{3}$ All non-hydrogen atoms were refined with anisotropic displacement parameters, and hydrogen atoms were placed in idealized positions and refined as rigid atoms with the relative isotropic displacement parameters. The surface morphology and height of the vertically-aligned hexagonal microrods on HOPG substrate were measured with Atomic Force Microscope (Asylum Research MPD-3D-SA ${ }^{\mathrm{TM}}$, Japan).

\section{References}

1. M. C. Burla, R. Caliandro, M. Camalli, B. Carrozzini, G. L. Cascarano, L. D. Caro, C. Giacovazzo, G. Polidori, R. Spagna. J. Appl. Crystallogr. 2005, 38, 381-388

2. Crystal Structure 4.0: Crystal Structure Analysis Package; Rigaku Corp., Tokyo, Japan, 2000-2010.

3. G. M. Sheldrick. Acta Crystallogr. Sect. A 2008, 64, 112-122 


\section{Spectral data of $2-\mathrm{Me}-\alpha-\mathrm{CD}$}

2-Me- $\alpha-\mathrm{CD}$ was synthesized from $\alpha-\mathrm{CD}$ in three steps according to the literature method. ${ }^{[1]}$

Spectral data: ${ }^{1} \mathrm{H}$ NMR (400 MHz, DMSO- $\left.d_{6}\right): \delta 4.99(\mathrm{~d}, J=3.2 \mathrm{~Hz}, 6 \mathrm{H}), 4.69(\mathrm{~s}, 6 \mathrm{H}), 4.51(\mathrm{t}, J=5.7 \mathrm{~Hz}, 6 \mathrm{H})$, $3.88(\mathrm{t}, J=9.3 \mathrm{~Hz}, 6 \mathrm{H}), 3.63(\mathrm{~m}, 6 \mathrm{H}), 3.55(\mathrm{~m}, 6 \mathrm{H}), 3.48(\mathrm{~s}, 18 \mathrm{H}), 3.42(\mathrm{t}, J=9.1 \mathrm{~Hz}, 6 \mathrm{H}), 3.11(\mathrm{dd}, J=9.7 \mathrm{~Hz}$, $3.4 \mathrm{~Hz}, 6 \mathrm{H}) ;{ }^{13} \mathrm{C}$ NMR (400 MHz, DMSO- $\left.d_{6}\right): \delta 100.1,83.2,82.1,73.3,72.1,60.4,59.8$; MALDI TOF-MS: calcd for $\mathrm{C}_{42} \mathrm{H}_{72} \mathrm{O}_{30}+\mathrm{Na}^{+}: 1078.99[\mathrm{M}+\mathrm{Na}]^{+}$; found: 1079.00

(A)

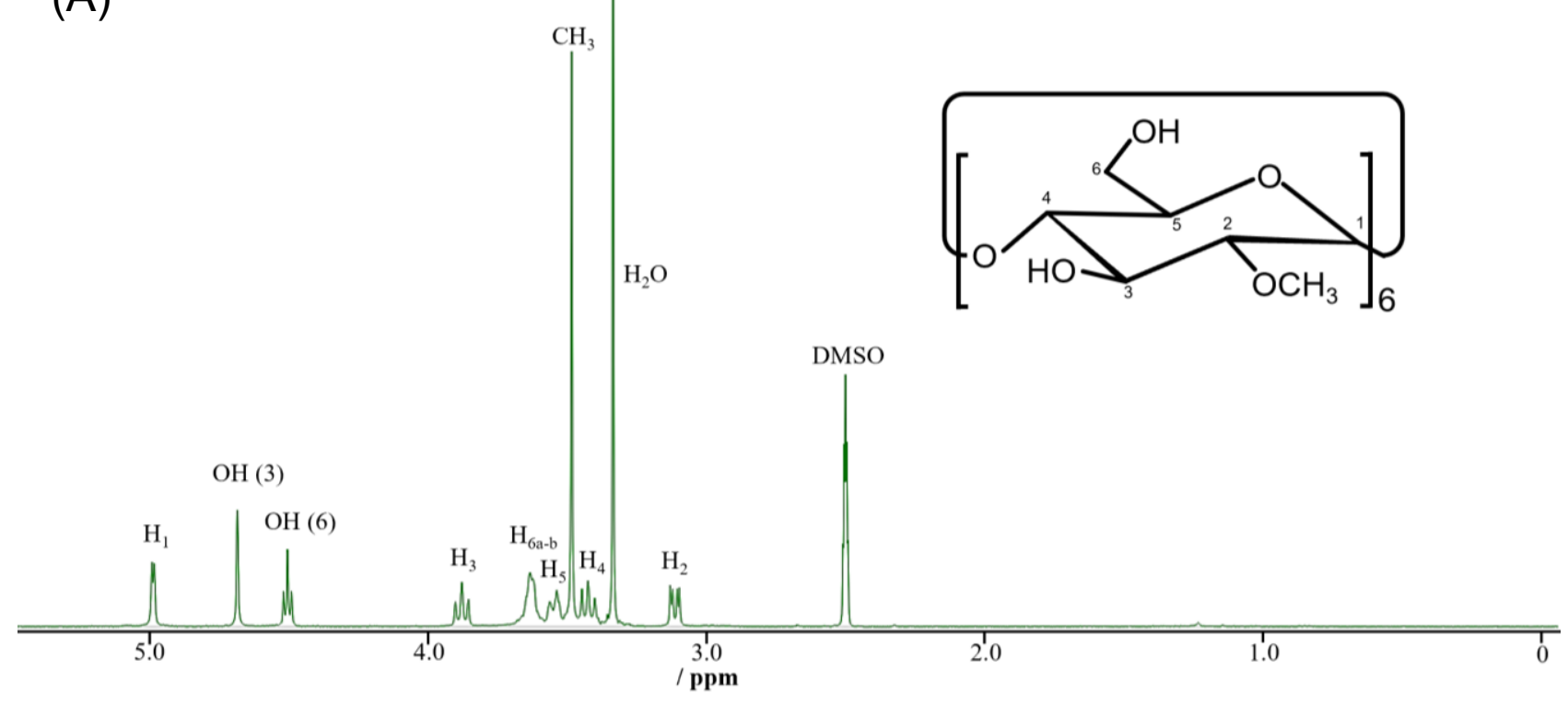

(B)

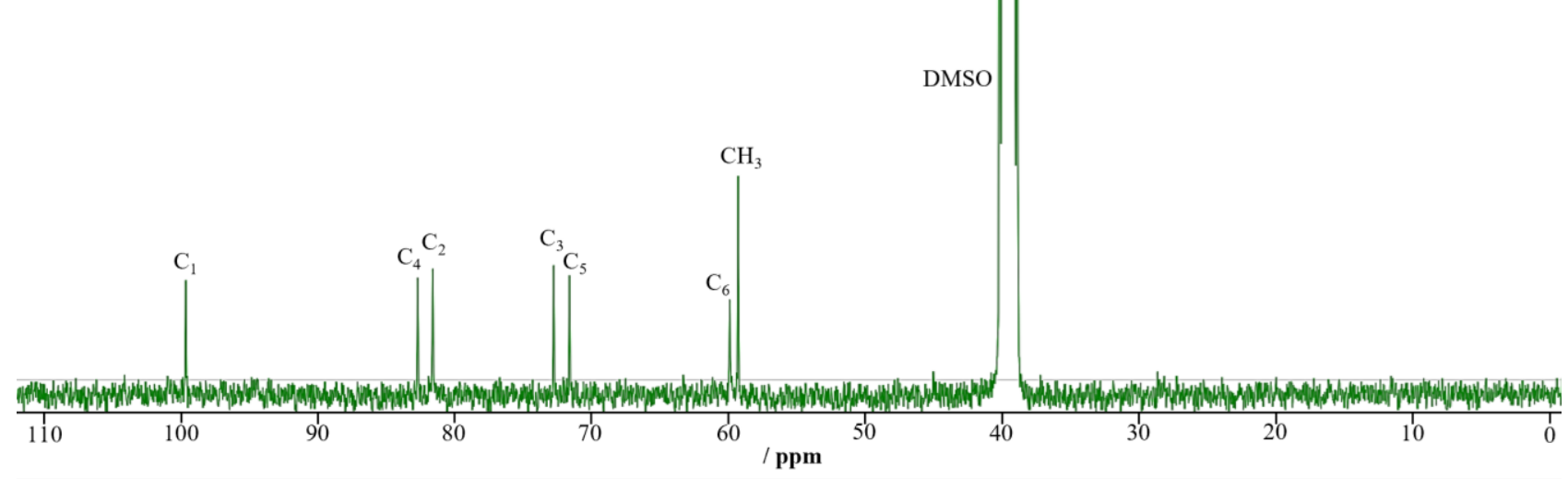

Figure S1. (A) ${ }^{1} \mathrm{H}$ and (B) ${ }^{13} \mathrm{C}$ NMR spectra of 2-Me- $\alpha-\mathrm{CD}$ in DMSO- $d_{6}$.

\section{Reference}

1. K. Takeo, H. Mitoh, K. Uemura, Carbohydr. Res. 1989, 187, 203. 
3. SEM images of 2-Me- $\alpha-C D$ precipitates formed by mixing a methanol solution of 2-Me- $\alpha-$ CD with different poor solvents
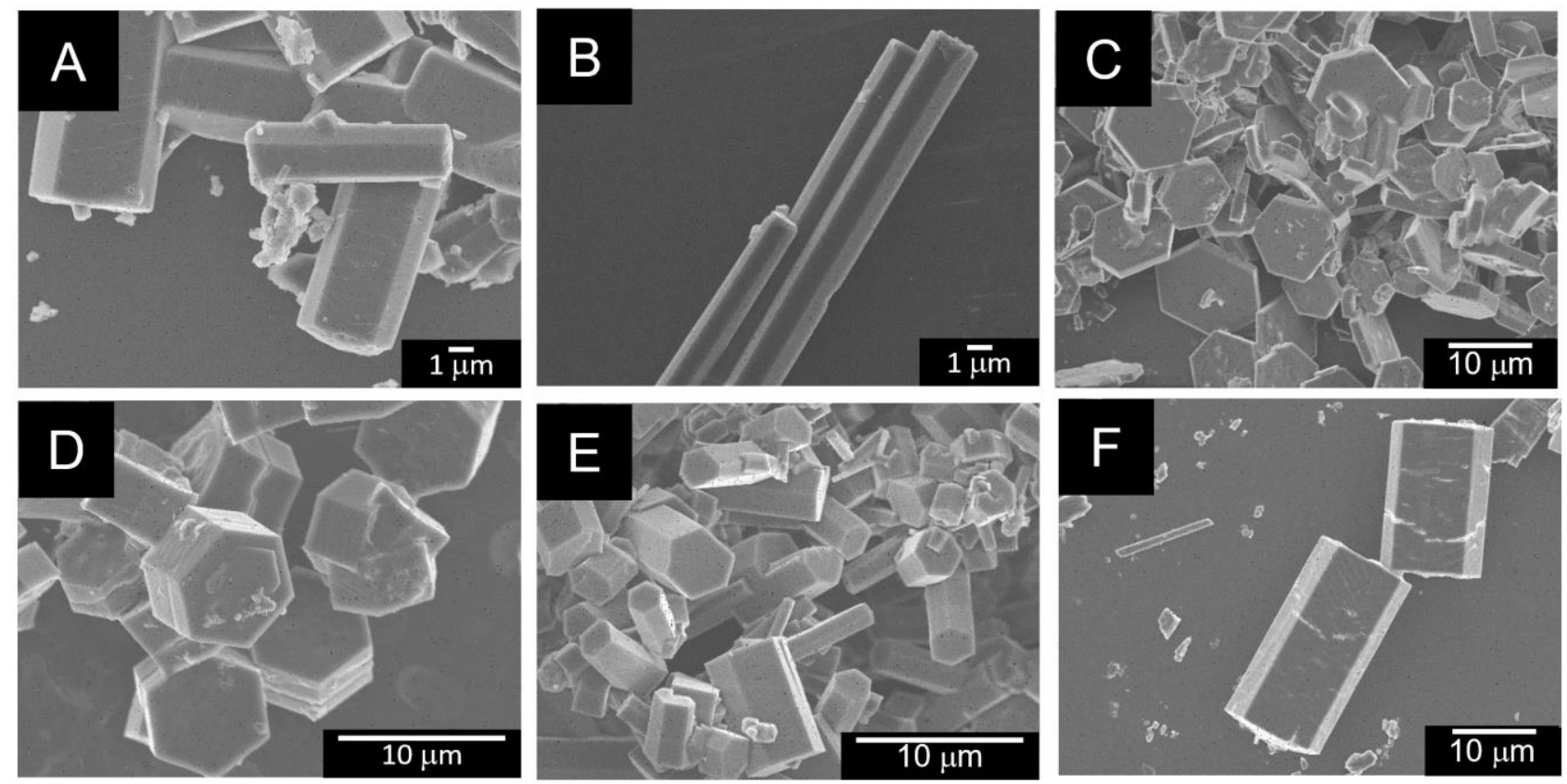

Figure S2. SEM images of 2-Me- $\alpha-C D$ structures formed by dropping a $2-\mathrm{Me}-\alpha-\mathrm{CD} /$ methanol solution [9.5 mM] into (A) methylcyclohexane, (B) 1,2-dimethylcyclohexane, (C) 1,4-dioxane, (D) pentamethylene sulfide, (E) ethyl acetate, (F) 1-hexanol and then standing at room temperature until solids precipitate. 


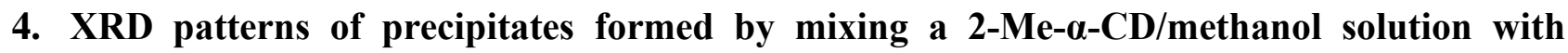
various poor solvents and then standing at room temperature
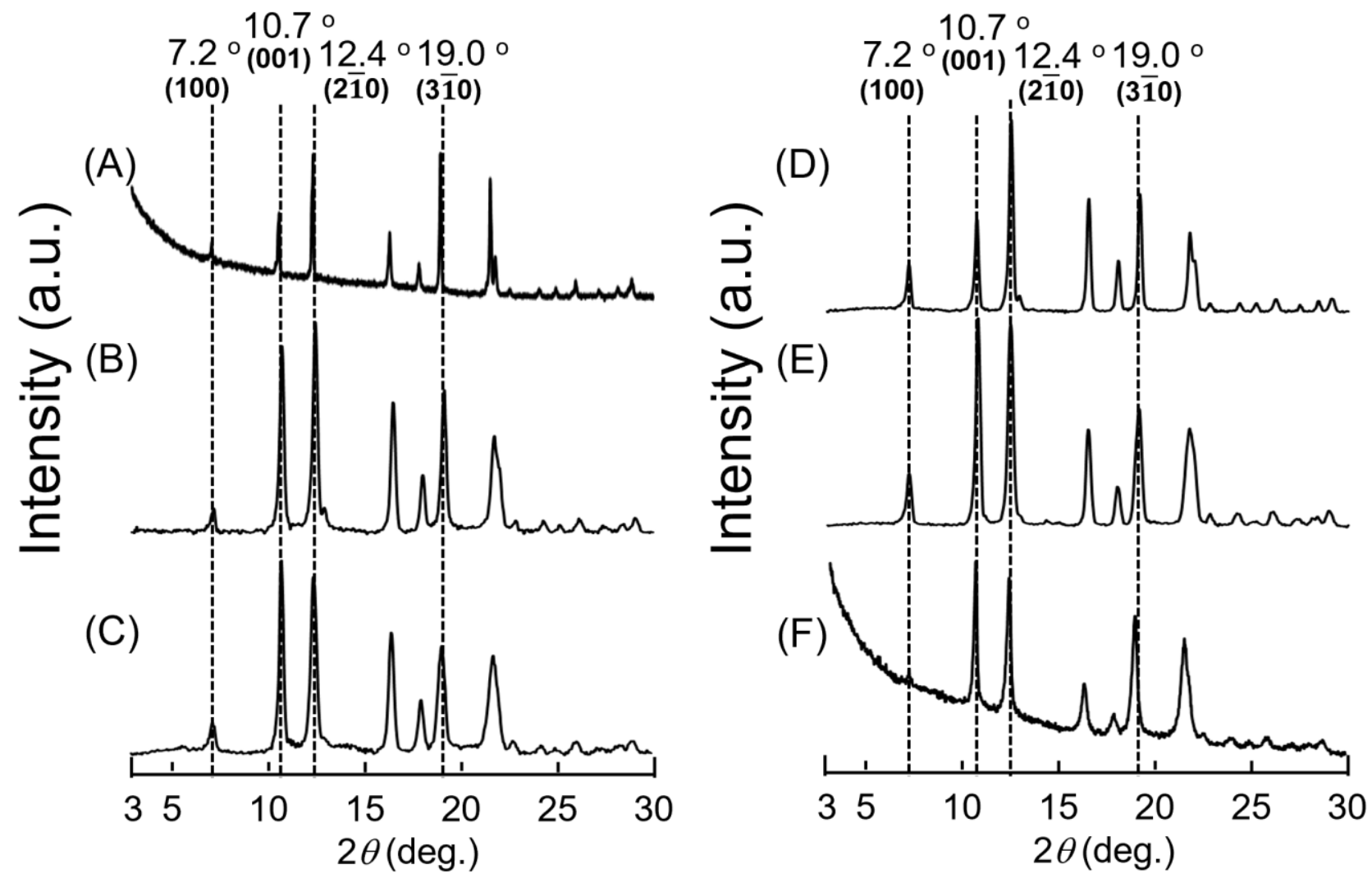

Figure S3. XRD patterns of 2-Me- $\alpha-\mathrm{CD}$ structures formed by dropping a 2-Me- $\alpha-\mathrm{CD} /$ methanol solution [9.5 mM] into (A) methylcyclohexane, (B) 1,2-dimethylcyclohexane, (C) 1,4-dioxane, (D) pentamethylene sulfide, (E) ethyl acetate, (F) 1-hexanol and then standing at room temperature until solids precipitate. 


\section{Crystal structure of 2-Me- $\alpha-C D$ - benzene inclusion complex}

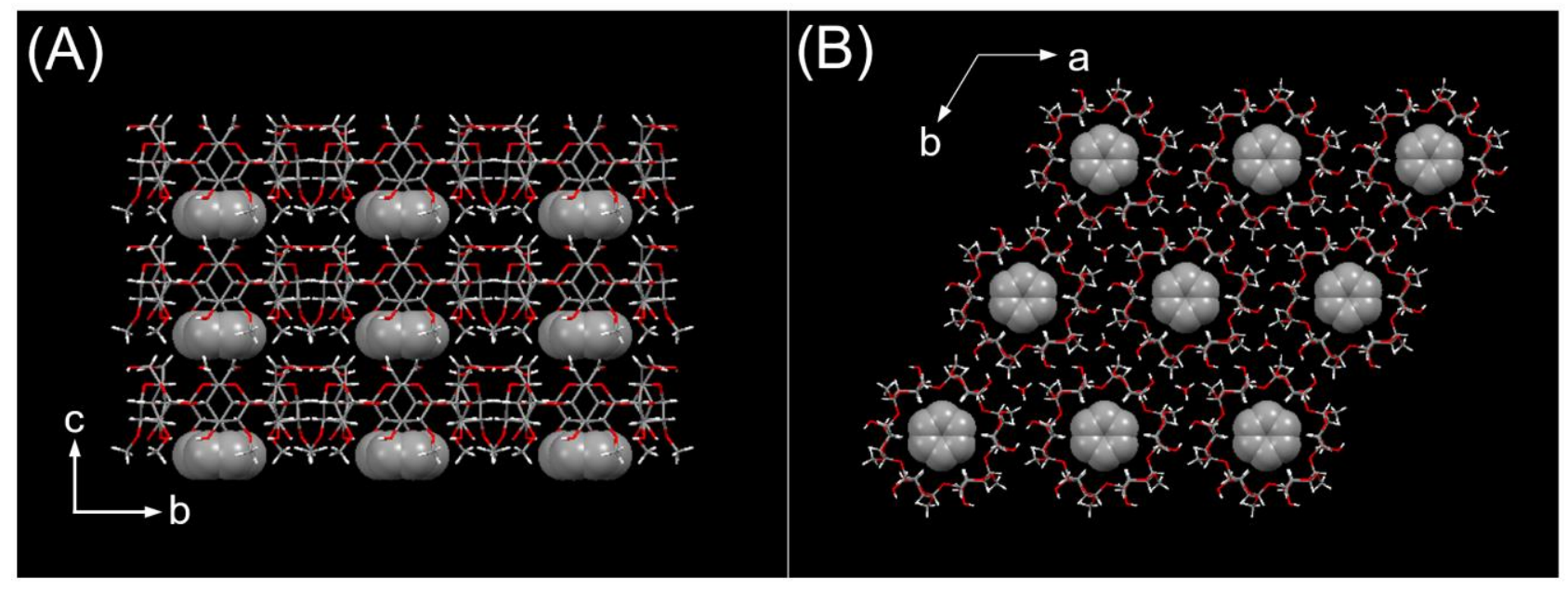

Figure S4. Crystal structure of 2-Me- $\alpha$-CD-benzene inclusion complex displayed in (A) side view and (B) top view. 2-Me- $\alpha-\mathrm{CD}$ is shown with a cylinder representation, whereas benzene is shown with a space-filling representation. Hydrogen atoms of benzene have been omitted for clarity. 

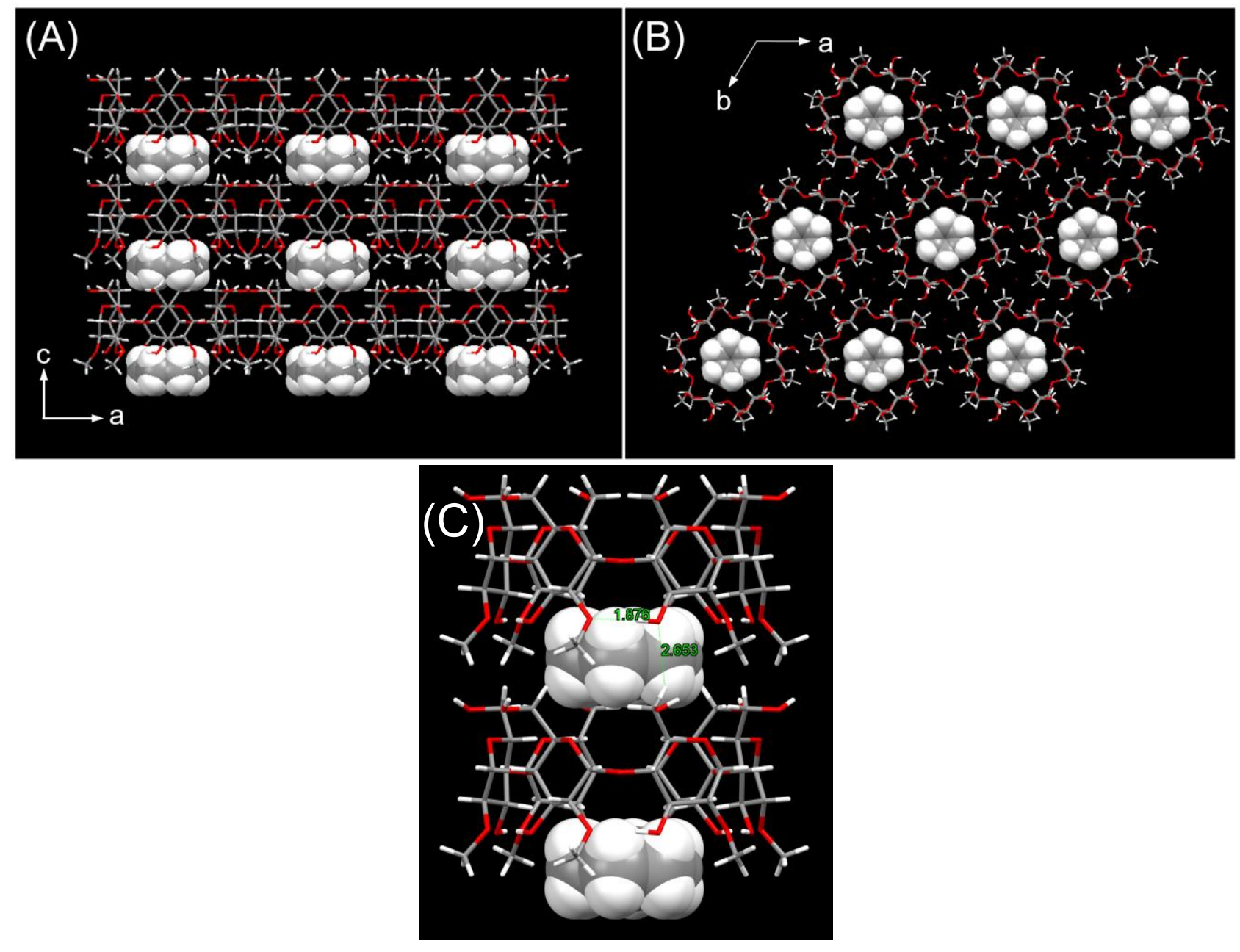

Figure S5. Crystal structure of 2-Me- $\alpha-C D$-cyclohexane inclusion complex shown in (A \& C) side view and (B) top view. 2-Me- $\alpha-C D$ is shown with cylinder representation, whereas cyclohexane is shown with space-filling representations. 